\title{
Molecular Recognition of the Antiretroviral Drug Abacavir: Towards the Development of a Novel Carbazole-Based Fluorosensor
}

\author{
Krzysztof Ryszard Idzik • Piotr J. Cywinski • \\ Charles G. Cranfield • Gerhard J. Mohr • \\ Rainer Beckert
}

Received: 29 September 2010 / Accepted: 28 December 2010 /Published online: 11 January 2011

(C) The Author(s) 2011. This article is published with open access at Springerlink.com

\begin{abstract}
Due to their optical and electro-conductive attributes, carbazole derivatives are interesting materials for a large range of biosensor applications. In this study, we present the synthesis routes and fluorescence evaluation of newly designed carbazole fluorosensors that, by modification with uracil, have a special affinity for antiretroviral
\end{abstract}

K. R. Idzik $(\bowtie) \cdot$ R. Beckert

Institute of Organic and Macromolecular Chemistry,

Friedrich-Schiller-University Jena,

Humboldstraße 10,

07743 Jena, Germany

e-mail: krzysztof.idzik@pwr.wroc.pl

P. J. Cywinski • G. J. Mohr

Institute of Physical Chemistry,

Friedrich-Schiller-University Jena,

Lessingstrasse 10,

07743 Jena, Germany

P. J. Cywinski $(\square)$

Department of Physical Chemistry, Institute of Chemistry,

University of Potsdam,

Karl-Liebknecht-Strasse 24-25,

14476 Potsdam-Golm, Germany

e-mail: piotr.cywinski@uni-potsdam.de

C. G. Cranfield

Biomolecular Photonics Group, University Hospital Jena,

Nonnenplan 2-4,

07740 Jena, Germany

\section{G. J. Mohr}

Fraunhofer Institute for Reliability and Microintegration (IZM), Department of Polytronic Systems, Workgroup Sensor Materials, Josef-Engert-Straße,

93053 Regensburg, Germany drugs via either Watson-Crick or Hoogsteen base pairing. To an $\mathrm{N}$-octylcarbazole-uracil compound, four different groups were attached, namely thiophene, furane, ethylenedioxythiophene, and another uracil; yielding four different derivatives. Photophysical properties of these newly obtained derivatives are described, as are their interactions with the reverse transcriptase inhibitors such as abacavir, zidovudine, lamivudine and didanosine. The influence of each analyte on biosensor fluorescence was assessed on the basis of the Stern-Volmer equation and represented by Stern-Volmer constants. Consequently we have demonstrated that these structures based on carbazole, with a uracil group, may be successfully incorporated into alternative carbazole derivatives to form biosensors for the molecular recognition of antiretroviral drugs.

Keywords HIV. HAART. Antiretroviral drugs · Carbazole $\cdot$ Base pairing $\cdot$ Fluorescence spectroscopy

\section{Introduction}

Highly Active Anti-Retroviral Therapy (HAART) is currently the process by which human immunodeficiency virus (HIV) infection is controlled. The basic principle of HAART is to use a mixture of at least three antiretroviral drugs in combination. The basic regimen is to administer two nucleoside reverse transcriptase inhibitors plus one non-nucleoside reverse transcriptase inhibitor; or two nucleoside reverse transcriptase inhibitors plus one protease inhibitor. The aim of therapy is the long-term inhibition of HIV replication. Commonly patients undergoing HARRT 
therapy suffer from numerous side effects including abdominal pain, diarrhea, liver failure, hepatitis, and xeroderma. The ability to monitor antiretroviral drug concentration on an individual basis will therefore allow practitioners to create a patient specific regimen to reduce individual suffering. This would be particularly relevant to child patients where the clearance rate for drugs like abacavir has been reported to be twice that of adults $[1,2]$.

Normally, the pharmacokinetics of nucleotide analog reverse transcriptase inhibitors (NARTIs) such as abacavir are determined by the use of liquid chromatography, mass spectrometry, or the tandem use of both [3-5]. However these methods are typically slow, expensive and require a high degree of experimental expertise. A combination of these methods with optical techniques such as absorbance or fluorescence detection has also been reported [6-8], and in a few cases electrochemical detection methods have also been applied $[9,10]$. The increased use of fluorescence spectroscopy for detection of NARTIs would introduce numerous advantages, as fluorescence based techniques have higher sensitivity when compared to absorbance techniques, and are more specific and less susceptible to interferences due to low concentrations the fluorosensor and/or analyte [11]. When compared to other analytical techniques, such as gas chromatography or HPLC, fluorescence based techniques can also exhibit increased cost efficiency. Consequently, molecular sensors utilizing fluorescence are fast, reliable and can provide high sensitivity. We report here the synthesis routes and fluorescence properties of newly synthesized carbazole derivatives functionalized with a uracil moiety. As guanine is present in the structure of abacavir, this uracil moiety would have an affinity to abacavir via mimicking either Watson-Crick or Hoogsteen base pairing [12, 13].

Carbazole is a well-known hole-transporting and electroluminescent organic molecule. Carbazole derivatives, because of their chromic and electroconductive effects, are interesting materials for a large range of electrical, optical and electro-optical applications $[14,15]$. The use of conducting polymers in biosensor architecture has also attracted a lot of attention over the years [16]. Carbazole derivatives are also endowed with fluorescent absorptions in the ultra-violet spectrum, and emission in the visible part of the spectrum, making them useful for both single and multi-photon fluorescence detection [17].

When a long aliphatic chain is attached to the $N$ atom in the five-membered central ring of carbazole, the resulting molecule can be easily dissolved in most organic solvents, with a decrease in the melting temperature $[18,19]$. For this reason we created $\mathrm{N}$-octylcarbazole to act as the base structure for the carbazole-uracil derivatives presented here. Four different groups were attached to the opposite aromatic ring of this $\mathrm{N}$-octylcarbazole-uracil derivative; namely, thiophene (U1), furane (U2), ethylenedioxythiophene (U3) and an extra uracil (U4). We assume the interaction between our biosensor and the potential analyte is by the formation of a triplex, as depicted in Scheme 1, which shows the proposed interaction between the U1 and $\mathrm{U} 4$ derivatives and abacavir. The introduction of a uracil moiety to the carbazole core alters the photophysical properties of carbazole by altering the charge distribution within the molecule, which can then be observed by the shift of fluorescence towards the red. The uracil moiety then, via hydrogen binding, enables the molecule to play the role of an
Scheme 1 Proposed formation of (a) the 1:1 complex of 6-(5uracilyl)- $N$-octylcarbazole (U1) and (b) the 1:2 complex 3,6-bis (5-uracilyl)-N-octylcarbazole

(U4) that are formed with abacavir via Hoogsteen triple bonding a<smiles>[Y6]c1nc(N([Hg]OC2C(c3ccc4c(c3)c3cc(-c5cccs5)ccc3n4CCCCCCCC)=CNC2O[Tl])C2CC2)c2ncn(C3C=CC(CO)C3)c2n1</smiles>

b

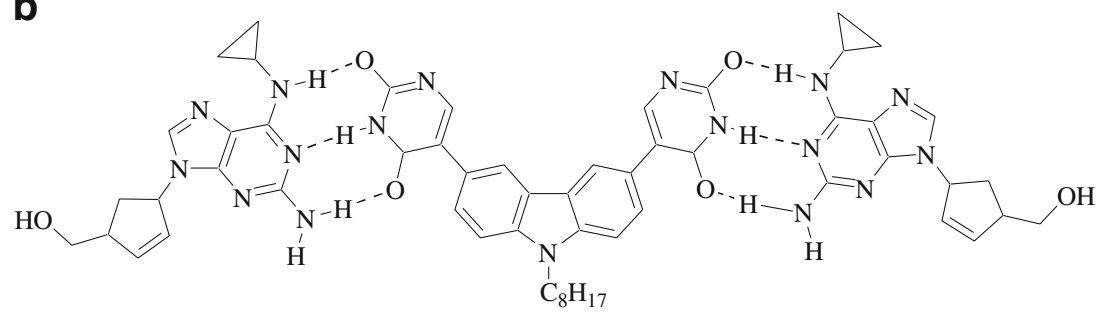


electron acceptor, with the NARTIs being the electron donors. The efficiency of this electron transfer can then be seen by fluorescence quenching of the fluorosensor [20].

The functionalization of $N$-octylcarbazole at the 3 or 6 positions by side groups such as thiophene, furane or ethylenedioxythiophene improves the chemical stability of carbazole and increases the mobility of the charge carrier in regioregular systems [21-23] which demonstrates that polymers based on polythiophene derivatives are good materials to be employed as active electrodes in electrochemical/electronic devices. It was to compare the photophysical properties, and to choose the best derivative for our purpose, that we employed thiophene, ethylenedioxy thiophene, and furane, as well as an extra uracil group, to conjugate to the N-octylcarbazole moiety.

Photophysical properties including absorbance and fluorescence emission spectra, fluorescence lifetime, and quantum yield were determined for all these $N$-octylcarbazole derivatives. The sensitivities of all the developed biosensors were tested against the NARTIs abacavir, lamivoudine, didanosine and zidovudine, in $0.1 \mathrm{M}$ Hepes Buffer ( $\mathrm{pH}$ 7.4). The quenching of the $N$-octylcarbazoleuracil derivatives as a result of binding to each analyte was assessed by means of steady-state fluorescence spectroscopy. The efficiency of quenching was assessed according to the Stern-Volmer equation and represented by the SternVolmer quenching constant.

\section{Experimental Section}

\section{Materials}

Abacavir was purchased from Sequoia Research Products (Pangbourne, UK) while Didanosine was obtained from TCI Europe (Eschborn, Germany). All other chemicals were purchased from Sigma-Aldrich (Germany) and used without any further purification. All solvents, both for chromatography and spectroscopy, as well as labware, were from Roth (Karlsruhe, Germany).

\section{Synthesis of Fluorosensors}

All chemicals, reagents, and solvents were used as received from commercial sources without further purification, except tetrahydrofuran (THF) and toluene, which were distilled over sodium/benzophenone. Scheme 2 illustrates the synthetic routes to obtain novel $N$-octyl-3-(2-aryl),6-(5uracilyl)carbazoles (U1-U3). These compounds were synthesized by a five-step procedure. Carbazole (1) was alkylated by 1-bromooctane in the presence of benzyltriethylammoniumchloride (BTEAC) as a phase-transfer catalyst to yield $N$-octylcarbazole (2) as described previously
[24]. Bromination of structure 2 at the 3,6-positions was achieved by adding $N$-bromosuccinimide (NBS) in chloroform. A palladium-catalyzed Stille-type coupling reaction was employed to obtain 3-aryl,6-bromo- $N$-octylcarbazole (4) from (2-tributylstannyl)aryl derivatives. In short, the brominated $N$-octylocarbazole (1 g, $2.29 \mathrm{mmol})$ (3) was placed in a $250 \mathrm{~mL}$ round two-bottom flask, under argon, in anhydrous toluene $(100 \mathrm{~mL})$. To this was added the 2 (tributylstannyl)aryl $(2.29 \mathrm{mmol})$ compounds and $\mathrm{Pd}$ $\left(\mathrm{PPh}_{3}\right)_{4}(0.230 \mathrm{~g}, 0.2 \mathrm{mmol})$. The resulting mixtures were stirred for $96 \mathrm{~h}$ at $120{ }^{\circ} \mathrm{C}$. After this time mixtures were cooled to room temperature. Water was then added and the resulting solutions were extracted with $50 \mathrm{~mL}$ portions of $\mathrm{CHCl}_{3}$. The combined organic layers were washed with $50 \mathrm{~mL}$ of brine, dried over $\mathrm{MgSO}_{4}$ and evaporated to a dark brown oil. The crude products were then purified over a chromatographic silica gel column (hexane/AcOEt, 10:1).

Suzuki coupling was employed in the next step to obtain the compounds at structure $\mathbf{5}$. The structure $\mathbf{4}$ compounds (1.60 mmol) were dissolved in $100 \mathrm{~mL}$ of absolute THF under argon. This solution was cooled to $-78{ }^{\circ} \mathrm{C}$ before $1.14 \mathrm{~mL}$ of sec-Butyllithium (sec-BuLi, 1.4 M in hexane, $1.60 \mathrm{mmol}$ ) was added. The reaction mixture was stirred for $20 \mathrm{~min}$ and 2-Isopropoxy-4,4,5,5-tetramethyl-1,3,2-dioxaborolane $(0.33 \mathrm{~mL}, 1.60 \mathrm{mmol})$ was added. After $24 \mathrm{~h}$ the reaction mixture was allowed to warm to room temperature and $40 \mathrm{~mL}$ of water was added. The solutions were extracted with $50 \mathrm{~mL}$ portions of ethyl acetate. The combined organic layers were washed with $20 \mathrm{~mL}$ of brine, dried over $\mathrm{MgSO}_{4}$ and evaporated to a brown oil. The products were purified by column chromatography (eluent: hexane/AcOEt, 9:1).

In the last step structure 5 compounds $(1.03 \mathrm{mmol})$ were then mixed with 5-bromouracil (134 $\mathrm{mg}, 0.70 \mathrm{mmol}), \mathrm{Pd}$ $\left(\mathrm{PPh}_{3}\right)_{4}(95 \mathrm{mg}, 0.082 \mathrm{mmol})$, and $2 \mathrm{M} \mathrm{Na}_{2} \mathrm{CO}_{3}$ aqueous solution $(15 \mathrm{~mL}, 30 \mathrm{mmol})$ in toluene $(100 \mathrm{~mL})$, and stirred at reflux under an argon atmosphere for $120 \mathrm{~h}$. Water $(150 \mathrm{ml})$ and $\mathrm{CHCl}_{3}(150 \mathrm{ml})$ were then added. The organic phases were separated and the water phases were extracted. Organic phases were collected together and washed with water, then brine solution, dried over anhydrous $\mathrm{MgSO}_{4}$, filtered, and the solvents left to evaporate off. The crude products were then purified over a chromatographic silica gel column (hexane/AcOEt, 3:1) to obtain the final structures of: U1, 3-(2-thienyl)-6-(5-uracilyl)- $N$-octylcarbazole; U2, 3-(2-furyl)-6-(5-uracilyl)- $N$-octylcarbazole; and U3, 3-[2-(3,4-ethylenedioxythienyl)]- $N$-octylcarbazole; (6).

In Scheme 3 we present a two-step synthesis of $\mathbf{U} 4,3,6-$ bis(5-uracilyl)- $N$-octylcarbazole (8). From structure $\mathbf{3}$ in Scheme 2, 3,6-dibromo- $N$-octylcarbazole reacts according to the Suzuki-type reaction with an excess of borolane derivatives to obtain structure 7 . The reaction between 3,6bis(4,4,5,5-tetramethyl-1,3,2-dioxaborolan-2-yl)- $N$-octyl- 
Scheme 2 Reaction conditions for the production of $\mathrm{U} 1, \mathrm{U} 2$ and U3: (i) $\mathrm{C}_{8} \mathrm{H}_{17} \mathrm{Br}$ (1 eq), BTEAC (0.4 eq), Benzene/ $\mathrm{NaOH}_{\mathrm{aq}} ; 90{ }^{\circ} \mathrm{C}, 12 \mathrm{~h}$; (ii) NBS (2.2 eq), $\mathrm{CHCl}_{3} ; 40{ }^{\circ} \mathrm{C}, 8 \mathrm{~h}$; (iii) 2-(Tributylstannyl)aryl (1 eq), $\mathrm{Pd}\left(\mathrm{PPh}_{3}\right)_{4}(0.08$ eq), Toluene $120{ }^{\circ} \mathrm{C}, 96 \mathrm{~h}$; (iv) 2-Isopropoxy4,4,5,5-tetramethyl-1,3,2-dioxaborolane (1.2 eq), sec-BuLi (1.2 eq), THF, $-78^{\circ} \mathrm{C}, 24 \mathrm{~h}$; (v) 5-Bromouracil (1.4 eq), $\mathrm{Pd}$ $\left(\mathrm{PPh}_{3}\right)_{4}\left(0.08\right.$ eq), $\mathrm{Na}_{2} \mathrm{CO}_{3 \text { aq }}$, Toluene, $90-100{ }^{\circ} \mathrm{C}, 120 \mathrm{~h}$
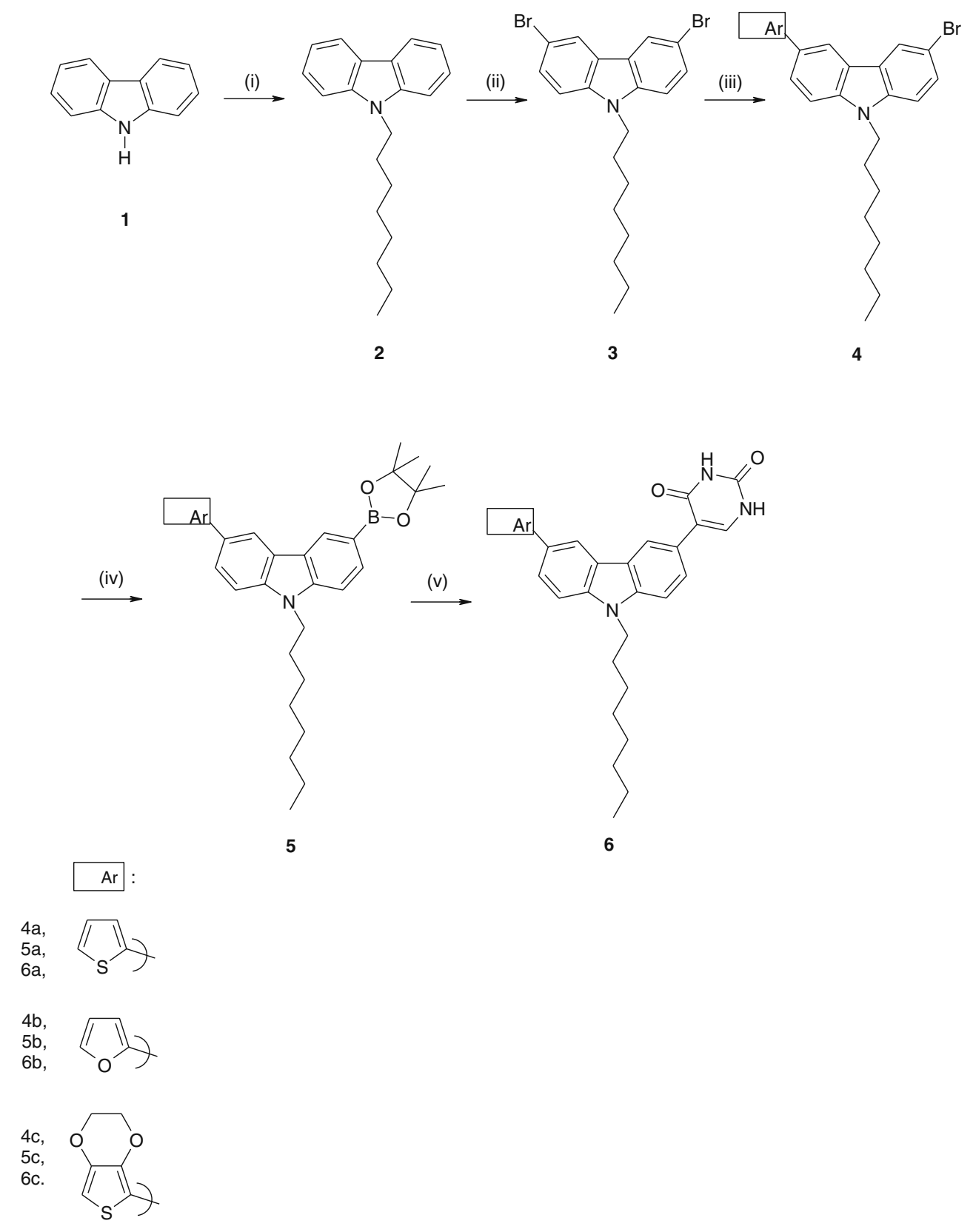

carbazole (7) and 5-bromouracil finally yields $\mathrm{U} 4$; 3,6-bis (5-uracilyl)- $N$-octylcarbazole (8).

For the preparation of 3,6-bis(4,4,5,5-tetramethyl-1,3,2dioxaborolan-2-yl)- $\mathrm{N}$-octylcarbazole (7), $\mathrm{N}$-octylocarbazole (2) $(0.874 \mathrm{~g}, 2.0 \mathrm{mmol})$ was dissolved in $100 \mathrm{~mL}$ of absolute THF under argon gas. This solution was cooled to $-78{ }^{\circ} \mathrm{C}$ before $3.43 \mathrm{~mL}$ of sec-BuLi $(1.4 \mathrm{M}$ in hexane, $4.8 \mathrm{mmol}$ ) was added. The reaction mixture was stirred for $20 \mathrm{~min}$ and 2-isopropoxy-4,4,5,5-tetramethyl-1,3,2-dioxaborolane $(0.98 \mathrm{~mL}, 4.8 \mathrm{mmol})$ was added. After $24 \mathrm{~h}$ the reaction mixture was allowed to warm to room temperature and $50 \mathrm{~mL}$ of water was added. The solution was extracted with $3 \times 50 \mathrm{~mL}$ portions of ethyl acetate. The combined organic layers were washed with $20 \mathrm{~mL}$ of brine, dried over $\mathrm{MgSO}_{4}$ and evaporated to a brown oil. The product was purified by column chromatography (eluent: hexane/ AcOEt, 9:1). The yield after purification by column chromatography was $0.87 \mathrm{~g}(82 \%)$ of a light yellow solid.

3,6-bis(5-uracilyl)-N-octylcarbazole (8) was prepared by mixing $7(0.4 \mathrm{~g}, 0.75 \mathrm{mmol})$ with 5-bromouracil $(0.403 \mathrm{~g}$, $2.1 \mathrm{mmol}), \mathrm{Pd}\left(\mathrm{PPh}_{3}\right)_{4}(138 \mathrm{mg}, 0.12 \mathrm{mmol})$, and $2 \mathrm{M}$ $\mathrm{Na}_{2} \mathrm{CO}_{3}$ aqueous solution $(20 \mathrm{~mL}, 40 \mathrm{mmol})$ in toluene $(100 \mathrm{~mL})$, and stirring at reflux under a argon atmosphere for $120 \mathrm{~h}$. Water $(150 \mathrm{ml})$ and $\mathrm{CHCl}_{3}(150 \mathrm{ml})$ were then added. The organic phase was separated and the water phase was extracted with $3 \times 50 \mathrm{~mL}$ of chloroform. Organic 
Scheme 3 Reaction conditions for the production of 3,6-bis(5uracilyl)- $N$-octylcarbazole, U4: (vi) 2-Isopropoxy-4,4,5,5-tetramethyl-1,3,2-dioxaborolane (2.4 eq), sec-BuLi (2.4 eq), $\mathrm{THF},-78{ }^{\circ} \mathrm{C}, 24 \mathrm{~h}$; (vii) 5Bromouracil (2.8 eq), $\mathrm{Pd}\left(\mathrm{PPh}_{3}\right)_{4}$ (0.12 eq), $\mathrm{Na}_{2} \mathrm{CO}_{3 \text { aq }}$, Toluene, $90-100{ }^{\circ} \mathrm{C}, 120 \mathrm{~h}$

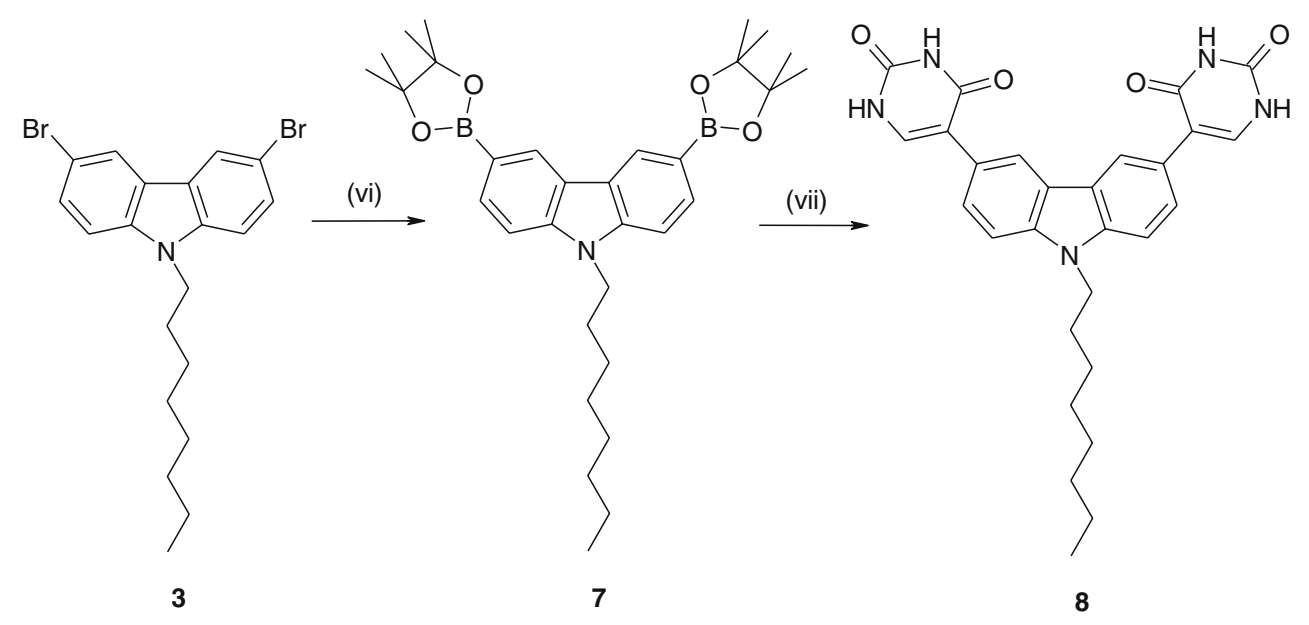

phases were collected and washed with water, then brine solution, dried over anhydrous $\mathrm{MgSO}_{4}$, filtered, and the solvents left to evaporate off. The crude product was purified over a chromatographic silica gel column (hexane/ AcOEt, 3:1) to give $\mathrm{U} 4$, (8).

\section{Methods}

${ }^{1} \mathrm{H}$ NMR spectra were recorded in deuterated chloroform $\left(\mathrm{CDCl}_{3}\right)$ on a Brucker 250 spectrometer. Preparative column chromatography was carried out on glass columns of different sizes packed with silica gel 60 (Merck) (0.035$0.070 \mathrm{~mm}$ ). Mass spectra were recorded on a MAT SSQ 710 from Finnigan. Fluorescence spectra of U1-U4 were measured in a FluoroLog-3 spectrofluorometer (Horiba Jobin Yvon, Bensheim, Germany). Fluorescence was excited at the last excitation band and recorded in the usual rectangular configuration in a $1-\mathrm{cm}$ cubic quartz cuvette (Hellma, Mühlheim, Germany) placed in a cuvette holder, whose temperature was maintained at $25 \pm 0.2{ }^{\circ} \mathrm{C}$. Both, excitation and emission slits were set to $5 \mathrm{~nm}$ bandpass. Fluorescence quantum yield was measured on a C9920-02 Absolute PL Quantum Yield Measurement System (Hamamatsu) with an integrate sphere unit and a Xenon lamp as the monochromatic excitation light source. The decays of fluorescence were collected using an Edinburgh Instruments CD900 single photon counting spectrometer equipped with a hydrogen-filled coaxial flash lamp as an excitation source. The measurements were carried out with the emission monitored at a $90^{\circ}$ angle to the excitation. The data were collected in 1,023 channels with 10,000 counts at the peak, and the time calibration was 0.053 ns per channel. The data were analyzed by a least squares reconvolution procedure using the software package provided by Edinburgh Instruments. Goodness of fit was judged in terms of $\chi^{2}$ value and residuals distribution, and the values for $\chi^{2}$ of 1.3 or lower indicated the appropriateness of the kinetic model and the resulting parameters. The fluorescence decays were measured using an excitation wavelength of $275 \mathrm{~nm}$, and fluorescence emission was collected at the maximum of the steady-state fluorescence emission spectra, being $410 \mathrm{~nm}$ (U2), $430 \mathrm{~nm}$ (U3), $475 \mathrm{~nm}$ (U1) and $480 \mathrm{~nm}$ (U4).

\section{Sample Preparation}

Previously prepared solutions of each of the studied fluorosensors $\left(5 \times 10^{-4} \mathrm{M}\right)$ in DMF were used for studying their interaction with the various analytes. An aliquot $(50 \mu \mathrm{L})$ of each solution was dissolved in $5 \mathrm{ml}$ of HEPES buffer $0.1 \mathrm{M}$ at $\mathrm{pH} 7.4\left(5 \times 10^{-6} \mathrm{M}, \mathrm{OD} \leq 0.1\right)$ and then $3 \mathrm{ml}$ of this solution was transferred to a $1 \times 1 \mathrm{~cm}$ quartz cuvette (Hellma GmbH). Small aliquots $(10 \mu l$ the smallest) of the analytes (up to a total volume of $300 \mu \mathrm{L}$ ) were then added to the cuvette. The $\mathrm{pH}$ was controlled using a $\mathrm{pH}$ meter (Hanna Instruments), and the value remained constant throughout all the measurements.

\section{Results and Discussion}

\section{Photophysical Properties of Fluorosensors}

Electronic absorbance peaks $\left(\lambda_{\text {abs }}\right)$, fluorescence emission spectra $\left(\lambda_{\mathrm{em}}\right)$, molar absorptivity $(\varepsilon)$, quantum yields $\left(\phi_{\mathrm{f}}\right)$ and fluorescence lifetimes $\left(\tau_{\mathrm{f}}\right)$ were separately determined for all the fluorosensors in 0.1 M HEPES buffer. Electronic absorbance, fluorescence excitation and emission spectra of $10 \mu \mathrm{M}$ solution of the U1 derivative are shown in Fig. 1a. A mono-exponential fit of U1's fluorescence lifetime is presented in Fig. 1b. The fluorescence lifetimes for all derivatives, measured at their emission peaks, were in the range of 7.2 to $8.5 \mathrm{~ns}$ in $0.1 \mathrm{M}$ HEPES buffer (excitation $275 \mathrm{~nm}$ ). Characteristically these compounds show absor- 
a

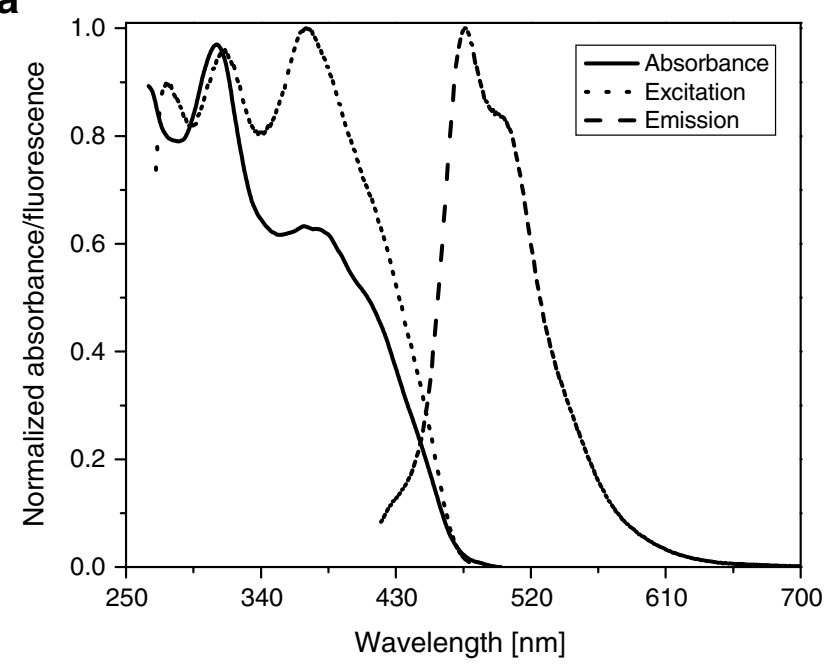

b

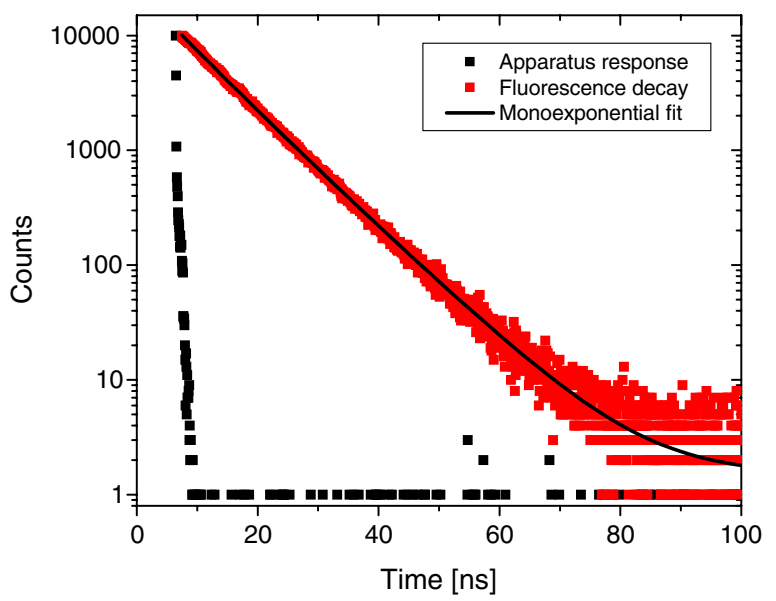

Fig. 1 a Electronic absorbance, fluorescence excitation and emission spectra; b fluorescence lifetime decay of U1

bance in the range from 250 to $400 \mathrm{~nm}$. In the case of U1, the fluorescence emission spectrum is broad and positioned in the blue-green range with maxima at $475 \mathrm{~nm}$ and $500 \mathrm{~nm}$, which is characteristic for carbazole moieties [25]. All the photophysical properties of all tested biosensors are gathered in Table 1.

Table 1 Photophysical properties of studied fluorosensors. Maxima of absorbance $\left(\lambda_{\text {abs }}\right)$, extinction coefficient $(\varepsilon)$, maxima of fluorescence emission $\left(\lambda_{\mathrm{em}}\right)$, quantum yield $\left(\phi_{\mathrm{f}}\right)$, fluorescence lifetime $\left(\tau_{\mathrm{f}}\right)$,<smiles></smiles>

Abacavir

Zidovudine<smiles>Nc1ccn(C2CS[C@@H](CO)O2)c(=O)n1</smiles>

Lamivudine<smiles>O=c1nc[nH]c2c1ncn2[C@H]1CC[C@@H](CO)O1</smiles>

Didanosine

Scheme 4 Chemical structures of the nucleotide analog reverse transcriptase inhibitors used to characterise the $\mathrm{N}$-octylcarbazole derivatives

\section{Base Paring Between Fluorosensors and NARTIs}

The structures of NARTIs used within the study are shown in Scheme 4. The fluorosensors U1-U4 were each incubated with an increasing concentration (up to $50 \mu \mathrm{M}$ ) of each quencher, and their emission spectra were recorded. These $N$-octylcarbazole derivatives exhibited a marked decrease in fluorescence upon addition of the quencher as a consequence of base pairing (Figs. 2 and 3). The drop in fluorescence is attributed to its quenching by photo-induced electron transfer between the biosensor and nucleotide after the hydrogen bonds are formed. This mechanism of interaction between fluorescent dyes and quenchers has been long established and is well described [26]. The Stern-Volmer constant, $\mathrm{K}_{\mathrm{SV}}$, was used to evaluate the fluorescence quenching efficiency, according to the SternVolmer equation:

$\frac{I_{0}}{I}=1+k_{q} \tau_{0}(Q)=1+K_{S V}(Q)$

and goodness of fit of the fluorescence lifetime decays $\left(\chi^{2}\right)$ characteristic for each of the fluorosensors

\begin{tabular}{lccrrr}
\hline Carbazole & $\lambda_{\text {abs }}(\mathrm{nm})$ & $\varepsilon\left(\mathrm{L} \mathrm{mol}^{-1} \mathrm{~cm}^{-1}\right)$ & $\lambda_{\mathrm{em}}(\mathrm{nm})$ & $\phi_{\mathrm{f}}$ & $\tau_{\mathrm{f}}(\mathrm{ns})$ \\
\hline U1(tio) & 310,380 & 14200 & 480,510 & 0.276 & $8.1 \pm 1.0$ \\
U2 (furan) & 275,295 & 15920 & 430 & 0.243 & $7.2 \pm 0.7$ \\
U3 (ditiof) & 278,375 & 14500 & 435,485 & 0.343 & $8.2 \pm 1.2$ \\
U4 (diura) & 272,330 & 17540 & 485,515 & 0.397 & $8.5 \pm 1.1$ \\
\hline
\end{tabular}


a

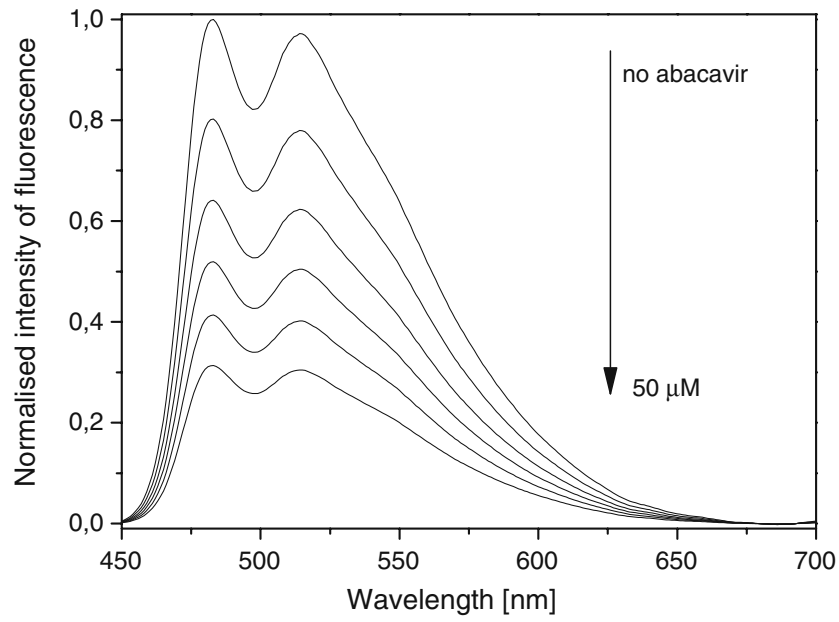

b

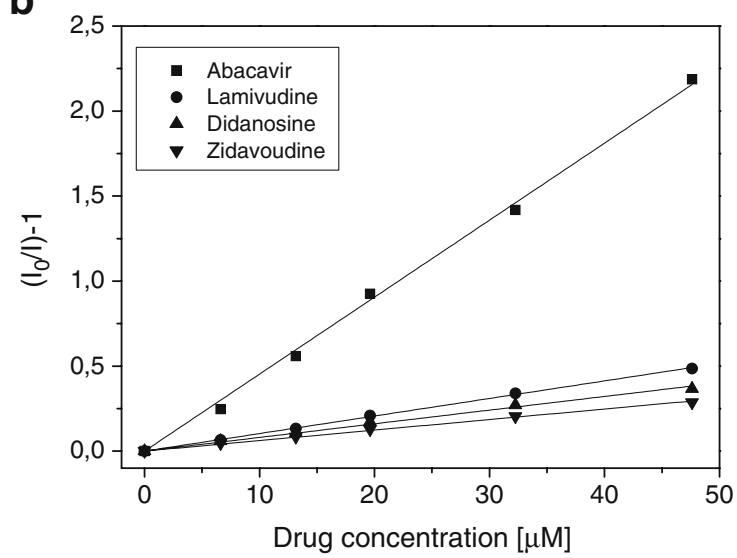

Fig. 2 a Fluorescence emission spectra $\left(\lambda_{\mathrm{exc}}=350 \mathrm{~nm}\right)$ for the quenching of U4 by abacavir.; b Stern-Volmer plots $\left(\lambda_{\mathrm{em}}=515 \mathrm{~nm}\right)$ for all the studied nucleotide analog reverse transcriptase inhibitors. The concentration of abacavir changes from 0 to $50 \mu \mathrm{M}$

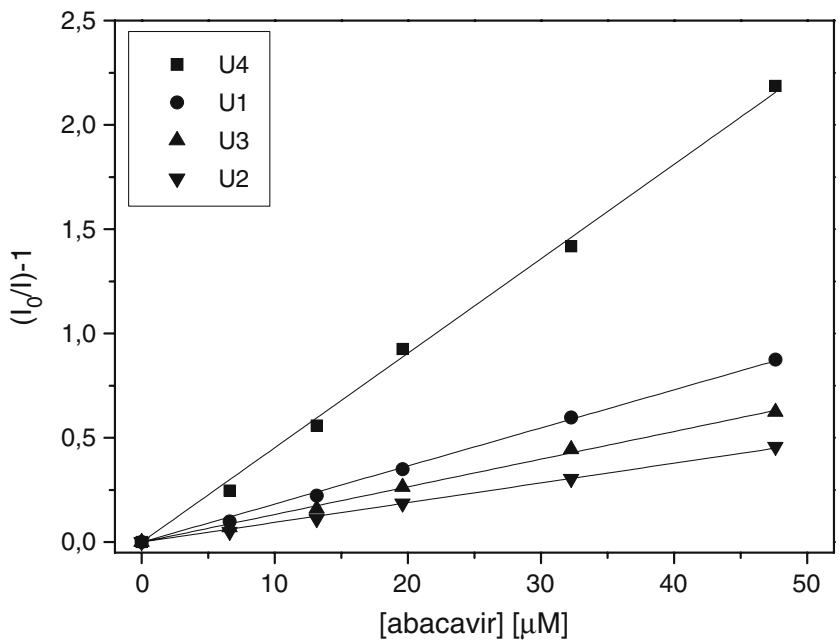

Fig. 3 Stern-Volmer plots for fluorosensors U1-U4 interacting with abacavir. The concentration of abacavir changes from 0 to $50 \mu \mathrm{M}$ where $k_{q}$ is the rate of biosensor quenching, $I$ is fluorescence intensity in the presence of the quencher (Q), $I_{0}$ and $\tau_{0}$ are the fluorescence intensity and lifetime in the absence the quencher respectively.

The fluorescence spectra of U4 in the presence of an increasing concentration of abcavir are shown in Fig. 2 a. A decrease in fluorescence intensity (more than 3 fold) is observed upon the addition of up to $50 \mu \mathrm{M}$ abacavir, producing a Stern-Volmer constant $\left(K_{\mathrm{SV}}\right)$ of $4.6 \times$ $10^{4} \mathrm{M}^{-1}$. The Stern-Volmer plots corresponding to the fluorescence quenching of U4 in the presence of all the NARTIs studied are presented in Fig. 2b. This was done to evaluate the selectivity of the fluorosensor to abacavir over didanosine, zidovudine and lamivudine since they are commonly administrated in combination with abacavir. The Stern-Volmer constants for all studied $N$-octylcarbazole derivatives, with all quenchers, are presented in Table 2 .

The highest $K_{\mathrm{SV}}$ values, and consequently the strongest quenching, were found for $\mathrm{U} 4$, which possesses two uracil moieties. Typically, U4 quenching was 3-5 fold stronger than for the single-uracil $N$-octylcarbazoles, being in the range of $6.2 \times 10^{3} \mathrm{M}^{-1}$ for zidovudine to $45.3 \times 10^{3} \mathrm{M}^{-1}$ for abacavir. For the derivatives U1-U3 the Stern-Volmer constants for all of the studied analytes were in the range of 3.7-18.3 $\times 10^{3} \mathrm{M}^{-1}$ for U1, 0.6-9.5 $\times 10^{3} \mathrm{M}^{-1}$ for U2 and $0.9-13.2 \times 10^{3} \mathrm{M}^{-1}$ for $\mathrm{U} 3$. We attribute this enhanced selectivity of the fluorosensor to abacavir to the presence of guanine in its structure. It has already been demonstrated using NMR spectrosopy that guanine binds to uracil via triple hydrogen bonding stronger than with thymine, adenine or even cytosine $[27,28]$. In the case of thymine and cytidine, only weak hydrogen interactions are observed; and in the case of adanine, uracil is only cabable of forming wobble base pairing. We also tested the interaction of the fluorosensor against metal ions such as $\mathrm{Na}^{+}, \mathrm{K}^{+}, \mathrm{Ca}^{2+}$ and pyrophosphate PPi. We observed up to 5\% (PPi) and 10\% $\left(\mathrm{K}^{+}\right.$and $\mathrm{Na}^{+}$) of abacavir induced quenching at $150 \mathrm{mM}$ concentration of each of the possible metal interferents. In the case of $\mathrm{Ca}^{2+}$, the induced quenching was $18 \%$, possibly due to coordination of uracil by the calcium ion [29, 30].

Table 2 Stern-Volmer constants $\left(K_{\mathrm{SV}}\right) \times 10^{3}\left[\mathrm{M}^{-1}\right]$ of the fluorosensors when exposed to the various nucleotide analog reverse transcriptase inhibitors

\begin{tabular}{lrrrr}
\hline Analyte & U1 (tio) & U2 (furan) & U3 (ditio) & U4 (diura) \\
\hline Abacavir & $18,3 \pm 0,3$ & $9,5 \pm 0,1$ & $13,2 \pm 0,2$ & $45,3 \pm 0,7$ \\
Lamivudine & $6,2 \pm 0.2$ & $2,6 \pm 0,1$ & $4,5 \pm 0,2$ & $10,3 \pm 0,2$ \\
Didanosine & $4,8 \pm 0,1$ & $1,3 \pm 0,1$ & $3,1 \pm 0,1$ & $8,1 \pm 0,2$ \\
Zidovudine & $3,7 \pm 0,1$ & $0,6 \pm 0,1$ & $0,9 \pm 0,1$ & $6,2 \pm 0.1$ \\
\hline
\end{tabular}


When the fluorosensor had already been presented to another analyte by hydrogen bonding, for example in the presence of abacavir, no further effect was observed. On the other hand, when abacavir was was added in the presence of PPi or the other metal ions, there was a marked increase in fluorescence quenching. This would indicate that abacavir exerts a stronger influence on the fluorescence response of the fluorosensors than do metal ions or phosphates that might also be present in the aqueous media.

Quenching as a result of adding benzene, which has no heteroatoms, was also tested. No appreciable change in fluorescence intensity was observed (results not shown). This gives clear evidence that the uracil moiety interacts with the drugs by formation of hydrogen bonds, which is what subsequently affects the fluorescence of the $\mathrm{N}$ octylcarbazole unit. To confirm the formation of the
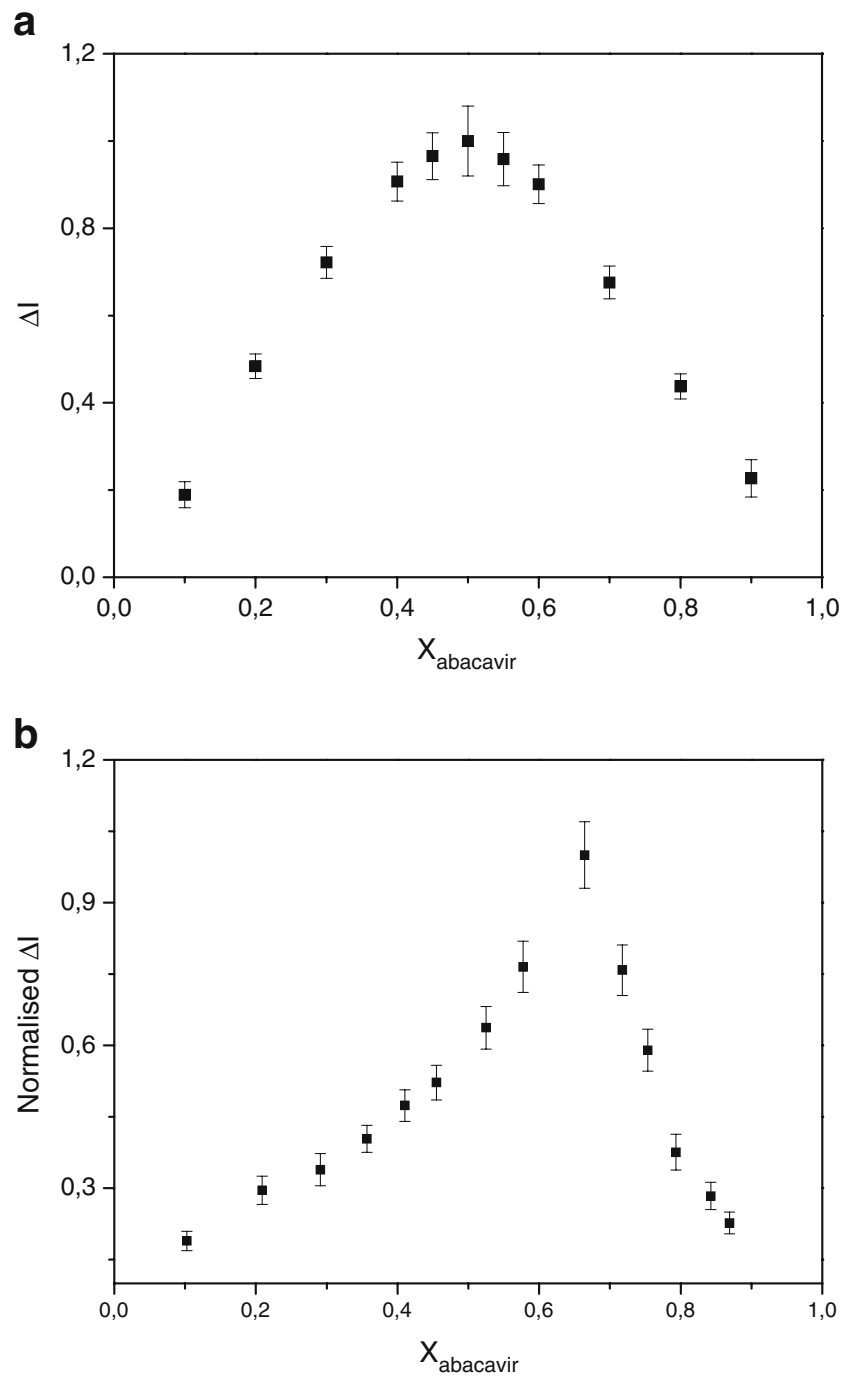

Fig. 4 Job plots for the complexation of U1 (a) and U4 (b) with abacavir in 0.1 M HEPES buffer pH 7.4, $\left(\lambda_{\text {exc }}=350 \mathrm{~nm}\right)$. The data presented are an average of 300 measurements
Table 3 Limits of detection $(L O D)[\mu \mathrm{g} / \mathrm{ml}]$ of the fluorosensors when exposed to the various nucleotide analog reverse transcriptase inhibitors

\begin{tabular}{lcccc}
\hline Analyte & U1 (tio) & U2 (furan) & U3 (ditio) & U4 (diura) \\
\hline Abacavir & 0.9 & 2.1 & 1.6 & 0.2 \\
Lamivudine & 2.7 & 7.2 & 4.5 & 1.1 \\
Didanosine & 3.5 & 9.6 & 5.5 & 1.5 \\
Zidovudine & 5.1 & 12.3 & 9.5 & 1.9 \\
\hline
\end{tabular}

complex between fluorosensors and abacavir we performed titration experiments using steady-state fluorescence spectroscopy. The Job's plots for the titration of U1 and U4 with abacavir are shown in Fig. 4. One can easily distinguish the formation of a 1:1 complex in the case of the U1:abacavir; while for $\mathrm{U} 4$ possessing two uracil moieties, a 1:2 stoichiometry can be concluded.

Hydrogen binding by its nature is considered as a mechanism which does not affect the lifetime of fluorescence [31]. We made an attempt, nevetheless, to confirm this mechanism by measuring fluorescence lifetime during the quenching of the fluorosensors. Analysis of the chemosensor fluorescence decays upon addition of the various drug concentrations revealed no change in the lifetime; however the time of measurment was elongated, indicating a loss of fluorescence intensity. This is clear evidence of the static character of the quenching, and the formation of stable complexes in the ground state [25].

In patients, after the administration of a $600 \mathrm{mg}$ oral dose of abacavir, its concentration, together with its metabolites, ranges from 0.5 to $7 \mathrm{mg} / \mathrm{ml}$ in human fluids $[32,33]$. In order to verify whether our fluorosensors are able to detect drugs in this range, we determined the limits of detection (LOD) for each of the NARTIs used according to the standard formula:

$L O D=3 \sigma / A$

Where $\sigma$ is a standard deviation of the fluorescence signal produced by the fluorosensor in the absence of a quencher; and $A$ is the slope of the dependence between the

Table 4 Tolerance limits $(T L)$ in $[\mathrm{mM}]$ for the detection $0.1 \mathrm{mM}$ abacavir in the presence of other nucleotide analog reverse transcriptase inhibitors using the carbazole fluorosensors

\begin{tabular}{lll}
\hline Analyte & \multicolumn{2}{l}{ Tolerance limits $[\mathrm{mM}]$} \\
\cline { 2 - 3 } & $\mathrm{U} 1-\mathrm{U} 3$ & $\mathrm{U} 4$ \\
\hline Lamivudine & $1.2 \pm 0.2$ & $2.1 \pm 0.2$ \\
Didanosine & $2.5 \pm 0.4$ & $3.2 \pm 0.5$ \\
Zidovudine & $4.1 \pm 0.9$ & $5.5 \pm 1.1$ \\
\hline
\end{tabular}


fluorosensor fluorescence and the concentration of the quencher.

The LOD for abacavir was found to be $200 \mathrm{ng} / \mathrm{ml}$ (4.2 $\mu \mathrm{M}$ ) being, advantageously, below concentration of abacavir usually found in real samples $(500 \mathrm{ng} / \mathrm{ml})$. All the LOD can be found in Table 3 .

Although the Stern-Volmer constant can indicate the differing influence of photo-induced electron transfer on a biosensor's fluorescence, it is not possible to distinguish, unambiguously, the influences of particular drugs in a heterogeneous mixture. Therefore we established the tolerance limits for each of the fluorosensors by a systematic study of the quenching effects of the drugs, in buffer, in the presence of $0.1 \mathrm{mM}$ abacavir. The concomitant species were tested at increasing concentration levels up to $6 \mathrm{mM}$, and, if interference occurred, the concentration of these species was reduced until the result was included in the confidence interval defined as significant by Student's $t$ test statistics $(P<0.05)$. The calculated tolerance levels that are sufficient for the analysis of abacavir are gathered in Table 4. Due to low LOD and high tolerance levels, the carbazole based fluorosensors have the potential to be used in multi-analyte array-based detection systems as well as in microfluidics platforms.

\section{Conclusions}

A series of $N$-octylcarbazole-uracil derivatives were synthesized using the Stille condensation and Suzuki coupling. These 6-(5-uracilyl)- $N$-octylcarbazole derivatives were tested for their affinity to antiretroviral drugs typically used in HAART. The bi-uracil derivative, in particular, exhibits high sensitivity towards abacavir, and moderate sensitivity to didanosine, zidovudine and lamivudine. Due to its low limits of detection, this fluorosensor has the potential to be applied to multi-analyte array-based detection platforms, as well as in microfluidics systems. Furthermore, the versatile chemistry of the carbazole allows an introduction of a functional group (amino, carboxylic or mercapto function) to the sensor molecule, which can be subsequently used for the covalent immobilization of the fluorosensor onto surfaces of nano-objects or biomolecules. This embedding of the 6-(5-uracilyl)- $N$-octylcarbazole derivative into polymer-based layers and nanoparticles to obtain new sensor materials, is now under investigation. These biosensors could then be used in the creation of novel HIVdrug pharmacokinetic research tools.

Acknowledgements This work was supported by the E.U. funded Marie Curie Transfer of Knowledge Project Sensor Nanoparticles for Ions and Biomolecules (SNIB) (MTKD-CT-2005-029554). Their support is gratefully acknowledged. K.R.I. and P.J.C. contributed equally to this paper.
Open Access This article is distributed under the terms of the Creative Commons Attribution Noncommercial License which permits any noncommercial use, distribution, and reproduction in any medium, provided the original author(s) and source are credited.

\section{References}

1. Cross SJ, Rodman JH, Lindsey JC, Robbins BL, Rose ChH, Yuen GJ, D'Angelo LJ (2009) Abacavir and metabolite pharmacokinetics in HIV-1-infected children and adolescents. J Acquir Immune Defic Syndr 51(1):54-59

2. Hughes W, McDowell JA, Shenep J, Flynn P, Kline MW, Yogev R, Symonds W, Lou Y, Hetherington S (1999) Safety and singledose pharmacokinetics of abacavir (1592U89) in human immunodeficiency virus type 1-infected children. Antimicrob Agents Chemother 43(3):609-615

3. Notari S, Mancone C, Alonzi T, Tripodi M, Narciso P, Ascenzi P (2008) Determination of abacavir, amprenavir, didanosine, efavirenz, nevirapine, and stavudine concentration in human plasma by MALDI-TOF/TOF. J Chromatogr B Analyt Technol Biomed Life Sci 863(2):249-257

4. Nageswara Rao R, Shinde DD (2009) Two-dimensional LC-MS/ MS determination of antiretroviral drugs in rat serum and urine. $\mathrm{J}$ Pharm Biomed Anal 50(5):994-999

5. Temghare G, Shetye S, Joshi S (2009) Rapid and sensitive method for quantitative determination of lopinavir and ritonavir in human plasma by liquid chromatography - tandem mass spectrometry. E J Chem 6(1):223-230

6. Bocedi A, Notari S, Narciso P, Bolli A, Fasano M, Ascenzi P (2004) Binding of anti-HIV drugs to human serum albumin. IUBMB Life 56(10):609-614

7. Lewis SR, White CA, Bartlett MG (2007) Simultaneous determination of abacavir and zidovudine from rat tissues using HPLC with ultraviolet detection. J Chromatogr B 850(1-2):4552

8. Suzuki K, Katayama M, Takamatsu K, Kaneko S, Miyaji K, Ishikawa H, Matsuda Y (2009) Improvement of sensitivity and selectivity of high-performance liquid chromatography for antiretroviral drugs (non-reverse transcriptase inhibitors) by diamondelectrode electrochemical and fluorescence detection. J Chromatogr A 1216(15):3117-3121

9. Dogan-Topal B, Uslu B, Ozkan S (2009) Voltammetric studies on the HIV-1 inhibitory drug efavirenz: the interaction between dsDNA and drug using electrochemical DNA biosensor and adsorptive stripping voltammetric determination on disposable pencil graphite electrode. Biosens Bioelectron 24(8):23582364

10. Turhan E, Uslu B (2008) Electroanalytical determination of opipramol in pharmaceutical preparations and biological fluids. Anal Lett 41(11):2013-2032

11. Cywinski PJ, Suriyanarayanan S, Moro AJ, Mohr GJ, Kutner W (2010) Chemosensors based on molecularly imprinted polymers. Top Curr Chem. doi:10.1007/128_2010_92

12. Neidle S (2008) Principles of nucleic acid structure, 1st edn. Academic, London

13. Westhof E, Fritsch V (2000) RNA folding: beyond Watson-Crick pairs. Structure 8(3):R55-R65

14. Bouchard J, Belletete M, Durocher G, Leclerc M (2003) Solvatochromic properties of 2, 7-carbazole-based conjugated polymers. Macromolecules 36(12):4624-4630

15. Gaupp CL, Reynolds JR (2003) Multichromic copolymers based on 3, 6-Bis(2-(3, 4-ethylenedioxythiophene))-N-alkylcarbazole derivatives. Macromolecules 36(17):6305-6315 
16. Gerard M, Chaubey A, Malhotra BD (2002) Application of conducting polymers to biosensors. Biosens Bioelectron 17 (5):345-359

17. Martin M, Breheret E, Tfibel F, Lacourbas B (1980) Two-photon stepwise dissociation of carbazole in solution. J Phys Chem 84 (1):70-72

18. Cloutet E, Olivero C, Adès D, Castex MC, Siove A (2002) Synthesis and blue luminescence of a soluble newly designed carbazole main-chain polymer. Polymer 43(12):3489-3495

19. Liu Y, Di C-A, Xin Y, Yu G, Liu Y, He Q, Bai F, Xu S, Cao S (2006) Organic light-emitting diode based on a carbazole compound. Synth Met 156(11-13):824-827

20. Seidel CAM, Schulz A, Sauer MHM (1996) Nucleobase-specific quenching of fluorescent dyes. 1. Nucleobase one-electron redox potentials and their correlation with static and dynamic quenching efficiencies. J Phys Chem 100(13):5541-5553

21. McCulloch I, Zhang W, Heeney M, Bailey C, Giles M, Graham D, Shkunov M, Sparrowe D, Tierney S (2003) Polymerisable liquid crystalline organic semiconductors and their fabrication in organic field effect transistors. J Mater Chem 13(10):2436-2444

22. Pelter A, Maud JM, Jenkins I, Sadeka C, Coles G (1989) Chemical and electrochemical syntheses of electroactive benzeoidheteroaromatic polymers. Tetrahedron Lett 30(26):3461-3464

23. Reynolds JR, Child AD, Ruiz JP, Hong SY, Marynick DS (1993) Substituent effects on the electrical conductivity and electrochemical properties of conjugated furanylphenylene polymers. Macromolecules 26(8):2095-2103

24. Cabaj J, Idzik K, Soloducho J, Chyla A (2006) Development in synthesis and electrochemical properties of thienyl derivatives of carbazole. Tetrahedron 62(4):758-764

25. Romero-Ale EE, Olives AI, Martín MA, Castillo BD, LópezAlvarado P, Menéndez JC (2005) Environmental effects on the fluorescence behaviour of carbazole derivatization reagents. Luminescence 20(3):162-169

26. Lakowicz JR (2006) Principles of fluorescence spectroscopy, 3rd edn. Springer Verlag, New York

27. Chan SI, Lee GCY, Schmidt ChF, Kreishman GP (1972) Guanineuracil base-pairing. Biochem Biophys Res Commun 46(4):15361543

28. Raszka M, Kaplan NO (1972) Association by hydrogen bonding of mononucleotides in aqueous solution. Proc Natl Acad Sci 69 (8):2025-2029

29. Kufelnicki A, Kupinska I, Jezierska J, Ochocki J (2002) Complexes of uracil (2, 4-Dihydroxypyrimidine) derivatives. Part I. $\mathrm{Cu}(\mathrm{II}), \mathrm{Ca}(\mathrm{II})$ and $\mathrm{Mg}(\mathrm{II})$ coordination with uracil and related compounds in aqueous solution. Pol $\mathrm{J}$ Chem 76 (1):1559-1570

30. Moreno-Luque CF, Griesser R, Ochocki J, Sigel H (2001) Properties of the Magnesium(II) and Calcium(II) complexes of 5- and 6-uracilmethylphosphonate $\left(5 \mathrm{Umpa}^{2-}\right.$ and $\left.6 \mathrm{Umpa}^{2-}\right)$ in aqueous solution. J Inorg Gen Chem 627(8):1882-1887

31. Cywinski PJ, Moro AJ, Ritschel T, Hildebrandt N, Löhmannsröben H-G (2010) Sensitive and selective fluorescence detection of guanosine nucleotides by nanoparticles conjugated with a naphthyridine receptor. doi:10.1007/s00216-010-4420-2

32. McDowell JA, Chittick GE, Ravitch JR, Polk RE, Kerkering TM, Stein DS (1999) Pharmacokinetics of $\left[{ }^{14} \mathrm{C}\right]$ abacavir, a human immunodeficiency virus type 1 (HIV-1) reverse transcriptase inhibitor, administered in a single oral dose to HIV-1-infected adults: a mass balance study. Antimicrob Agents Chemother 43 (12):603-608

33. Yuen GJ, Weller S, Pakes GE (2008) A review of the pharmacokinetics of abacavir. Clin Pharmacokinet 47(6):351371 